\title{
Effect of the polymorphic form of the seeds on the preferential crystallisation
}

\author{
L. Courvoisier, C. Gervais, L. Mignot, M.-N. Petit and G. Coquerel
}

Unité de Croissance Cristalline et de Modélisation Moléculaire $\left(U C^{2} M^{2}\right)$, UPRES EA 2659, IRCOF, Université de Rouen, rue Tesnière, 76821 Mont-Saint-Aignan cedex, France

\begin{abstract}
The 5(4'-methylphenyl)-5-methyl-hydantoin $(17 \mathrm{H})$ is known to crystallise in two polymorphic forms, $\alpha$ and $\beta$. Crystallographic parameters and molecular structure of the $17 \mathrm{H}$ polymorphs (orthorhombic and monoclinic forms) were first investigated. Then, the main kinetical parameters of the polymorphic transition are presented. The transition rate is so low that different seeding experiments can be undertaken. Seeded Isothermal Preferential Crystallisation (SIPC) method was applied to perform the separation of the enantiomers at a $2 \mathrm{~L}$ scale with two types of seeds, monoclinic and orthorhombic. Orthorhombic form was never obtained in the crops but the physical parameters of the crystals produced (size, form, ...) were strongly affected by the nature of the polymorph seeds.
\end{abstract}

\section{INTRODUCTION}

Polymorphism [1] is a key issue in many industries such as pharmaceutics, agro-chemistry, fine chemistry, pigment, and cosmetics... Physical and biological properties can be significantly affected by this phenomenon as recently illustrated in terms of commercial potentiality by drug Ritonavir [2].

Hydantoins have a wide range application in pharmaceutical and agrochemical domains [3]. The synthesis of the ( \pm )-5(4'-methylphenyl)-5-methyl-hydantoin (17H hereafter) is carried out from the corresponding ketone (4'methylacetophenone) using the 'one pot' Bucherer's reaction [4]

The first part of this study is devoted to the description of similarities between the two polymorphic forms of $17 \mathrm{H}$. Then the separation of the enantiomers of $17 \mathrm{H}$ is performed by means of Seeded Isothermal Preferential Crystallisation (SIPC). Finally, the influence of the polymorphic form seeded on the preferential crystallisation is discussed.

\section{RESULTS AND DISCUSSION}

\subsection{Overview of the orthorhombic and monoclinic forms of $17 \mathrm{H}$}

Polymorphism is the ability of a solid compound to exist in more than one crystalline form. Consequently, two polymorphs of the same compound can differ in physical properties that depend on the crystal lattice. The solubility of different polymorphs of the same compound reflects the differences in free energy between their respective crystalline states.

Two polymorphic forms of the $17 \mathrm{H}$ exist (table 1). The most stable one crystallises in the orthorhombic system (space group P2 $2_{2} 2_{1}$ ) while the metastable form (which exhibits a monotropic behaviour in the $\left[20^{\circ} \mathrm{C}\right.$-melting] temperature range) crystallises in the monoclinic system (space group P2 $2_{1}$. 
Table 1. Crystallographic parameters of $17 \mathrm{H}$ polymorphs.

\begin{tabular}{|l|c|c|c|c|}
\hline Form & Space group & $\mathrm{a}(\AA)$ & $\mathrm{b}(\AA)$ & $\mathrm{c}(\AA)$ \\
\hline Orthorhombic & $\mathrm{P} 2_{1} 2_{2} 2_{1}$ & 22.75 & 6.25 & 7.34 \\
\hline Monoclinic & $\mathrm{P} 2_{1}$ & 11.72 & 6.25 & 7.35 \\
\hline
\end{tabular}

These two forms show extensive similarities which result in:

$\Rightarrow$ Similar molecular conformations,

$\Rightarrow$ Identical hydrogen bond networks (involving every heteroatoms),

$\Rightarrow$ In the shape of identical molecular ribbons along the b direction, they are composed of two equivalent molecules regenerated one another by a twofold screw axis and closely linked together by the hydrogen bond network (figures 1,2 ), direction,

$\Rightarrow$ Similar molecular slices. They are made up of the ribbons translated along the $c$

$\Rightarrow$ Almost identical b and c crystallographic parameters,

$\Rightarrow$ Close lattice energies.

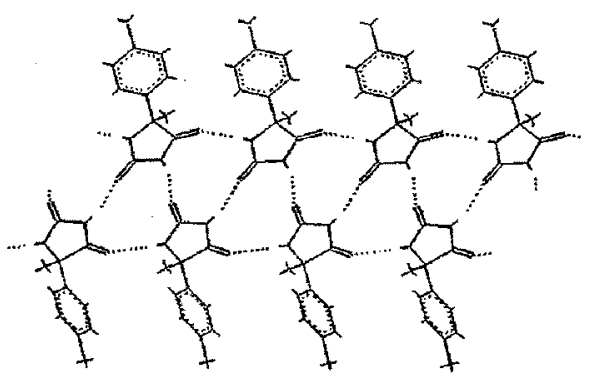

Figure 1. Molecular ribbons parallel to the b axis observed in the two structures of $17 \mathrm{H}$.
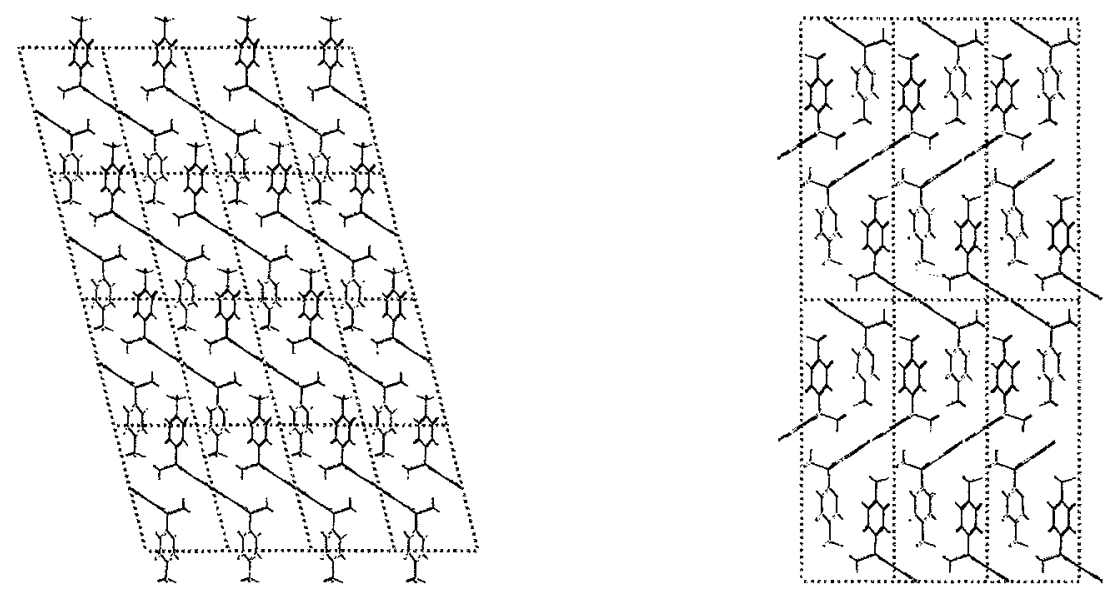

Figure 2. Projection along $\mathrm{b}$ of the 2 structures of $17 \mathrm{H}$ showing the differences of packing along the a direction. 
The kinetics of the polymorphic transformation from the monoclinic form into the orthorhombic one has been monitored in two solvents: acetone and ethanol.

The monoclinic form was prepared by cooling recrystallisation of pure $17 \mathrm{H}$. A $293 \mathrm{~K}$ saturated solution was placed in a glass stirred jacketed vessel maintained at $343 \mathrm{~K}$ and cooled at $277 \mathrm{~K}$ at the constant cooling rate of $25 \mathrm{~K} \mathrm{~h}^{-1}$. The crystal particles were separated from the mother liquor by filtration (glass filter $\mathrm{N}^{\circ} 4$, diameter $10 \mathrm{~cm}$ ).

The orthorhombic form was obtained by the following procedure: a suspension containing initially only the monoclinic form was maintained under continuous stirring at 308 $\mathrm{K}$ in acetone or ethanol. At a regular intervals, samples were removed for XRPD analysis (figure 3). The polymorphic purity of the samples was estimated by superimposition of X-ray powder diffraction patterns (powder diffractometer Siemens D5005) with that calculated from the crystal structures using the cerius ${ }^{2}$ software [5].

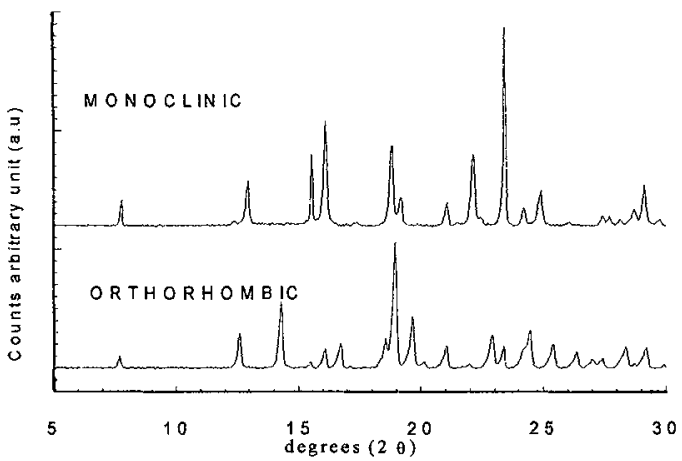

Figure 3. Powder X-Ray diffraction patterns of $17 \mathrm{H}$ polymorphs.

Without seeding, the kinetic of the polymorphism transition depends both on the ability of the stable form to nucleate and on the orthorhombic form growth.

Without seeding, the orthorhombic variety is detected after 40 days in acetone and 9 days in ethanol (table 2). The high degree of similarities between these two polymorphs is consistent with a low magnitude of $\Delta \mathrm{G}_{\text {mono } \rightarrow \text { ortho }}$ and therefore with a poor transformation rate.

Table 2. Duration required to obtain pure17H orthorhombic variety from a suspension containing initially only the monoclinic variety at $308 \mathrm{~K}$ (without seeding).

\begin{tabular}{|l|c|c|c|c|}
\cline { 2 - 5 } \multicolumn{1}{c|}{} & \multicolumn{2}{c|}{ Acetone } & \multicolumn{2}{c|}{ Ethanol } \\
\cline { 2 - 5 } \multicolumn{1}{c|}{} & $\begin{array}{c}\approx 5 \% \\
\text { orthorhombic }\end{array}$ & $\begin{array}{c}100 \% \\
\text { orthorhombic }\end{array}$ & $\begin{array}{c}\approx 5 \% \\
\text { orthorhombic }\end{array}$ & $\begin{array}{c}100 \% \\
\text { orthorhombic }\end{array}$ \\
\hline Duration (days) & 40 & 52 & 9 & 37 \\
\hline $\begin{array}{l}\text { Initial mass of solid } / \\
\text { Volume of solvent }\end{array}$ & \multicolumn{2}{c|}{$155 \mathrm{~g} / 2 \mathrm{~L}$} & \multicolumn{2}{c|}{$165 \mathrm{~g} / 1,7 \mathrm{~L}$} \\
\hline
\end{tabular}

\subsection{A brief description of SIPC process (Seeded Isothermal Preferential Crystallisation)}

According to the current knowledge, only 5-10\% of all chiral organic components crystallise as a conglomerate and $90 \%$ as racemic compounds [6]. In this instance, separation of the enantiomers via diastereomeric salts is an expensive and time-consuming process that is also occasionally accompanied by technical problems (filterability, recycling of the resolving agents ...). The separation of enantiomers by preferential cristallization is an attractive 
alternative, which however is only applicable to conglomerates. In other terms, the solubility diagram of the racemic compound must be that of conglomerate [7].

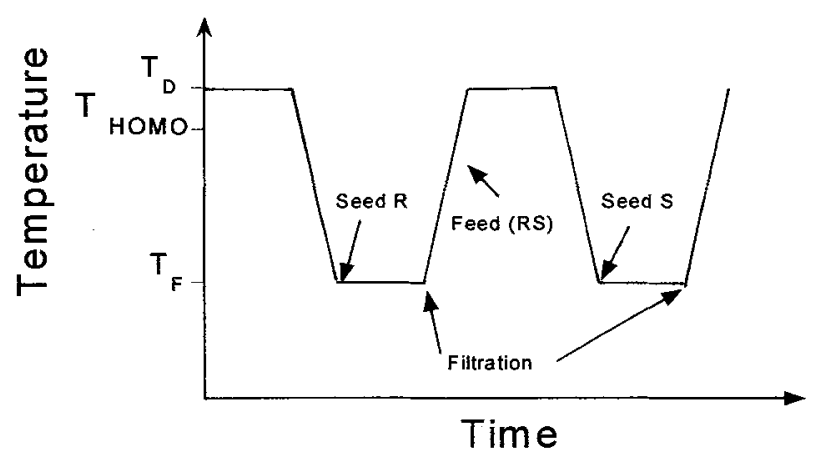

Figure 4. Temperature versus time profile for SIPC.

Figure 4 illustrates the sequence that is alternatively repeated for crystallization of each enantiomer: (i) The system composed of solvent, racemic mixture and $M$ mass unit enantiomeric excess (e.g. R) is homogenized at the Dissolution temperature $T_{D}>T_{\text {HOMO }}$ (Homogenization temperature) and then cooled down to $\mathrm{T}_{\mathrm{F}-\mathrm{SIPC}}$ (Filtration temperature) without any spontaneous nucleation. (ii) Seeding is implemented with very pure nuclei of enantiomer (e.g. R). (iii) The selective secondary and the crystal growth of the enantiomer $R$ occur up to the inversion of the optical rotation of the mother liquor. (iv) The suspension is filtered and yields $2 \mathrm{M}$ gram of $\mathrm{R}$ enantiomer. (v) $2 \mathrm{M}$ gram of $( \pm$ ) is thus added to the mother liquor to yield a system with $M$ mass of enantiomeric excess with the enantiomer $S$. The process is simply continued by repeating this cycle of operations; this affords alternatively the $\mathrm{R}$ and $\mathrm{S}$ enantiomers.

\subsection{Applications of SIPC by using seeds of the two $17 \mathrm{H}$ polymorphs}

The racemic mixtures of both the orthorhombic and monoclinic forms of $17 \mathrm{H}$ crystallise as conglomerates. Therefore, the resolution of the $17 \mathrm{H}$ (by means of SIPC) has been carried out in 2-methoxyethanol at a $2 \mathrm{~L}$ scale by using pure seeds of one of the two forms.

For both polymorphs, the parameters, summarized in table 3 , have been kept unchanged. The duration of the annealing at $T_{D}$ is 30 minutes. The stirring rate is maintained at $250 \mathrm{rpm}$ throughout the crystallisation.

Table 3. Initial conditions. Enantiomeric excess: $7.4 \%$.

\begin{tabular}{|c|c|c|}
\hline Mass of solvent $(\mathrm{g})$ & Mass of racemic mixture $(\mathrm{g})$ & Mass of enantiomer $(\mathrm{g})$ \\
\hline 1800 & 368.7 & 29.7 \\
\hline $\mathrm{T}_{\mathrm{D}}(\mathrm{K})$ & $\mathrm{T}_{\mathrm{H}}(\mathrm{K})$ & $\mathrm{T}_{\mathrm{F}}(\mathrm{K})$ \\
\hline 333 & 320 & 287 \\
\hline
\end{tabular}

The processes were monitored using the Focussed Beam Reflectance Measurement (F.B.R.M Lasentec (B) technique)[8]. The filtration (glass filter number 4 diameter $10 \mathrm{~cm}$ ) cakes obtained (crude material) were dried at room temperature (in order to avoid the polymorphic transition in the filtration cake) and weighted. The optical purities were measured at $365 \mathrm{~nm}$ 
with a polarimeter (Perkin Elmer 241 polarimeter equipped with a quartz of $1 \mathrm{dm}$ thermostated analytical tube ). Tables 4 and 5 summarize results in terms of mass and optical purity of the crops. Typical FBRM curves (count of chords versus time) are presented on figure 5 . The good reproducibility of the results has been demonstrated by three consecutives runs performed at two liter scale for each polymorphic form of the seeds.

Table 4. Results of SIPC seeding with monoclinic form

\begin{tabular}{|c|c|c|c|c|c|}
\hline Run & $\begin{array}{c}\text { Duration } \\
\text { (minutes) }\end{array}$ & $\begin{array}{c}\text { Mass of crude } \\
\text { material (g) }\end{array}$ & $\begin{array}{c}\text { Optical } \\
\text { purity (\%) }\end{array}$ & $\begin{array}{c}\text { Mass of pure enantiomer } \\
(\mathrm{g})\end{array}$ & Polymorphic form \\
\hline 1 & 23 & 122 & 56 & 68.3 & Monoclinic \\
\hline 2 & 26 & 128.3 & 52 & 66.7 & Monoclinic \\
\hline 3 & 24 & 124.6 & 55 & 68.5 & Monoclinic \\
\hline
\end{tabular}

Table 5. Results of SIPC seeding with orthorhombic form.

\begin{tabular}{|c|c|c|c|c|l|}
\hline Run & $\begin{array}{c}\text { Duration } \\
\text { (minutes) }\end{array}$ & $\begin{array}{c}\text { Mass of crude } \\
\text { material (g) }\end{array}$ & $\begin{array}{c}\text { Optical } \\
\text { purity (\%) }\end{array}$ & $\begin{array}{c}\text { Mass of pure enantiomer } \\
(\mathrm{g})\end{array}$ & Polymorphic form \\
\hline 4 & 83 & 94.6 & 90 & 85.1 & Monoclinic \\
\hline 5 & 85 & 94.8 & 91 & 86.2 & Monoclinic \\
\hline 6 & 83 & 94.8 & 90 & 85.3 & Monoclinic \\
\hline
\end{tabular}

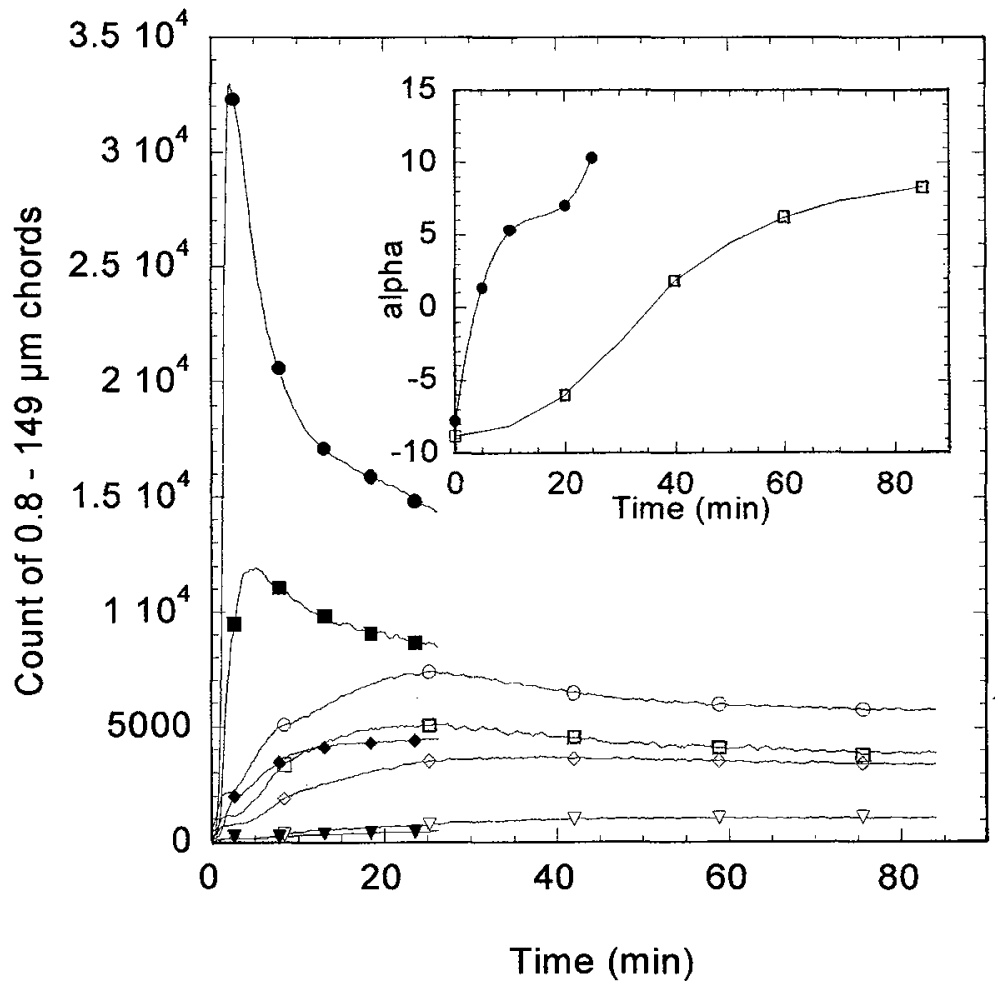

Figure 5. FBRM curve ( $\mathrm{C}_{\mathrm{h}} \mathrm{SD}$ of particles) obtained when the racemic mixture is seeded with orthorhombic form and with monoclinic form (black symbols).

Chords length ranges: $\bullet 0.8-15.6 \mu \mathrm{m} ; \mathbf{\square} 15.6-44.3 \mu \mathrm{m} ; \bullet 44.3-105 \mu \mathrm{m} ; \nabla 105-149 \mu \mathrm{m}$ In the insert, rotary power (alpha, $365 \mathrm{~nm}$ at $293 \mathrm{~K}$ ) of the mother liquor during the crystallisations 
FBRM technique is an in-line method which permits to monitor the evolution of particles in suspension by measuring their chord lengths during the crystallisation. The population of $3 \mathrm{D}$ particles is thus represented in a $1 \mathrm{D}$ space by means of chords size distribution $\left(\mathrm{C}_{\mathrm{h}} \mathrm{SD}\right)$. FBRM offers to monitor thousands of chords per second, producing a chord length distribution over the range 0.8 to $1000 \mu \mathrm{m}$.

When the monoclinic form is used as seeds, the in-line monitoring of the particle chords shows that a high secondary nucleation takes place during 3 minutes after the inoculation and results in a large population of small particles $(0.8-15.6 \mu \mathrm{m}$ chords; figure 6b; specific area $2.4 \mathrm{~m}^{2} \mathrm{~g}^{-1}$ ); the number of small chords peaks at about three times the number that is observed when using the orthorhombic seeds [9-11]. The mother liquor is very difficult to filtrate (filtration duration about 10 minutes, glass filter $\mathrm{N}^{\circ} 4$ ), that explains the poor optical purity of the crude crops.

When the orthorhombic form is used as seeds, the secondary nucleation rate increases smoothly up to a maximum at 25 minutes. The crystal growth is thus predominant during the whole entrainment process. Unexpectedly, the nature of the solid form is, at the threshold of detection (XRPD) only constituted by the monoclinic form. Due to the large crystal size (0.8$105 \mu \mathrm{m}$ chords; figure 6-a; specific area $0.9 \mathrm{~m}^{2} \mathrm{~g}^{-1}$ ), the mother liquor is easy to filtrate (about 1 minute with the same set-up). It results in a fairly good optical purity of the crude crops (table 5).
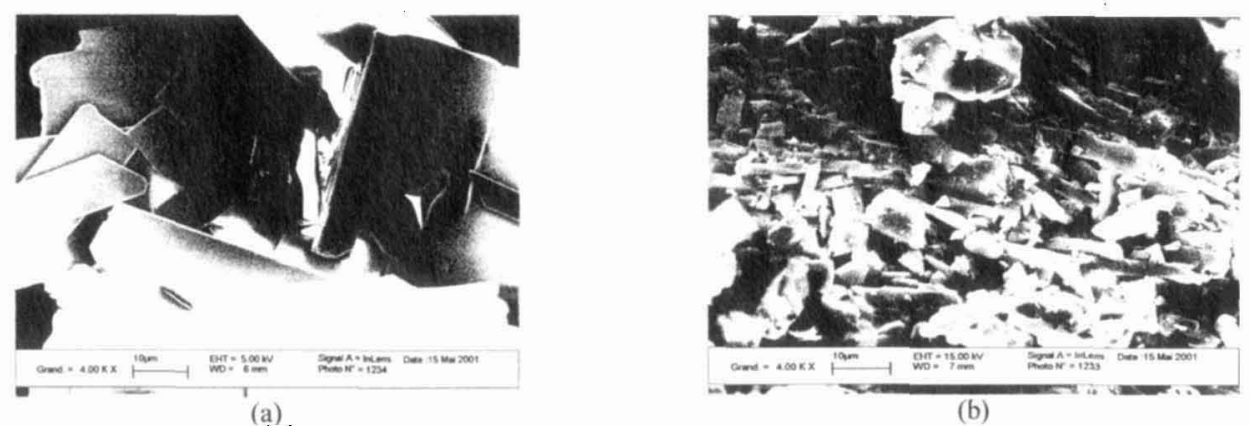

Figure 6. SEM photographs of crystals resulting from SIPC process seeded with orthorhombic form (a) and seeded with monoclinic form (b).

According to the results of the rotary power of the mother liquor versus time (figure 5), resulting from monoclinic or orthorhombic seeding, it could be inferred that the filtration only is detrimental to the use of the monoclinic form. Indeed, the performance of the entrainment (final maximum enatiomeric excess of the mother liquor) is greater $\left(10.5^{\circ}\right)$ with monoclinic seeding than with orthorhombic seeding $\left(8.5^{\circ}\right)$. Nevertheless, these results show that seeding with the stable form prevents from any uncontrolled offspring of nuclei, while we observed a lack of control during the entrainment when the monoclinic polymorph is seeded.

\section{CONCLUSION}

We have shown the importance of the polymorphic form of the seeds in the control of the kinetic factors during the implementation of the Seeded Isothermal Preferential Crystallisation. Indeed, it acts significantly on the quantitative results: weak yield and poor optical purity of the crude material when the metastable form is seeded. This is probably due to the difficulty in implementing this filtration. Conversely, the use of the stable polymorph allow to control the crystal size distribution and to produce large crystais with a narrow size distribution and a good filtrability. To our knowledge, in the context of preferential 
crystallisation, this is the first time that the influence of the variety of the seeds on the physical properties of the particles yielded have been demonstrated.

The separation of the $17 \mathrm{H}$ enantiomers is equally performed in our laboratory by means of a new crystallization technique (Auto Seeded Polythermic Preferential Crystallisation - AS3PC) $[12,13]$. A same comparative study is now in progress for AS3PC method.

\section{Acknowledgements}

The authors are grateful to Dr Dany Lemarchand, Groupe de physique des matériaux, UMR 6636, Université de Rouen, Dr Alain René Schoof, Stéphanie Manchon, Délégation Régionale Recherche et Technologie and Région Haute Normandie.

\section{References}

[1] Byrn S., Pfeiffer R., Ganey M., Hoiberg C. and Poochkian G., Pharmeuceutical Reasearch, 12 (1995) 945-954.

[2] Rodriguez-Hornedo N. and Murphy D., Journal of Pharmaceutical Sciences 88 (1999) 651-660.

[3] Dapporto P., Paoli P., Rossi P., Altamura M., Perrota M. and Nannicini R., Journal of Molecular Structure (Theochem) 532 (2000) 195-204.

[4] Bucherer H.T. and Steiner W., J.Prakt. Chem. 140 (1934) 291-316.

[5] Cerius ${ }^{2}$, Molecular Simulation Inc., vers. 4.1 (2000), Cambridge, U.K.

[6] Eliel E.L., Wilen S.H. and Mander L.N., Stereochemistry of Organic Compounds (John Wiley and Sons Inc., New York, USA, 1994) pp. 153-215 and pp. 297-322

[7] Jacques J., Collet A. and Wilen S.H., Enantiomers, Racemates and Resolution (Krieger Publishing Compagny; Malabar, Florida, 1991).

[8] Richmond W.R., Jones R.L. and Fawell P.D., Chemical Engineering Journal 71 (1998) 67-75; http://www.lasentec.com.

[9] Mullin J.W., Crystallisation (Second Edition, Butterworths \& Co, London, U.K, 1972) pp. 35-37.

[10] Ostwald W, Z. Zeitschrigt für Physikalische Chemie 22 (1897) 289-330.

[11] Ting H.H. and Mc-Cabe W.L., Ind. Eng. Chem 26 (1934) 1201-1207.

[12] Ndzié E., Cardinael P., Schoofs A.R, and Coquerel G., Tetrahedron Asymmetry 8 (17) (1997), 2913-2920.

[13] Courvoisier L., Ndzié E., Petit M.-N., Hedtmann U., Sprengard U. and Coquerel G., Chemistry letters 4 (2001) 364-365. 